\title{
Hubungan Kepuasan Kerja dengan Komitmen Organisasional Perawat di Rumah Sakit Prikasih Jakarta
}

\author{
${ }^{1}$ Nurul Zakiah, ${ }^{2}$ Rahmah Hida Nurrizka, ${ }^{3}$ Yuri Nurdiantami, ${ }^{4}$ Fathinah Ranggauni $H$ \\ 1,2,3,4Program Studi Kesehatan Masyarakat, Fakultas Ilmu Kesehatan, UPN "Veteran” Jakarta \\ Jl. RS Fatmawati, Pd. Labu, Cilandak, Kota Jakarta Selatan, 12450 \\ Email : nurul.zakiah30@gmail.com, rh.nurrizka@gmail.com, nurdiantamiyuri@upnvj.ac.id, \\ fathinahranggaunihardy@gmail.com
}

\begin{abstract}
ABSTRAK
Berdasarkan data Risnakes 2017, kepuasan kerja staf rumah sakit di DKI Jakarta sebagian besar di kategori sedang $(50,1 \%)$ dan tinggi $(25,2 \%)$. Perawat yang kepuasan kerjanya tinggi akan membantu orang lain dengan lebih antusias jauh melebihi harapan yang normal dalam pekerjaan mereka dan akan menimbulkan komitmen kepada rumah sakit tempat mereka bekerja. Tujuan penelitian ini untuk menganalisis hubungan kepuasan kerja dengan komitmen organisasional pada perawat di Rumah Sakit Prikasih. Desain penelitian ini adalah cross sectional dengan uji chi square. Sampel pada penelitian ini sebanyak 104 perawat yang diambil dengan teknik proportional sampling. Hasil penelitian menunjukkan prevalensi komitmen organisasional tinggi sebanyak 58 perawat $(55,8 \%)$ dan kepuasan kerja tinggi sebanyak 52 perawat $(50 \%)$, perawat dengan kepuasan kerja tinggi memiliki komitmen organisasional tinggi sebanyak 36 perawat $(69,2 \%)$, dan ada hubungan antara kepuasan kerja dengan komitmen organisasional ( $p$-value $=0,010)$ dengan nilai $\mathrm{PR}=1,875$ dan 95\% CI $=1,173-2,998$. Perawat yang mempunyai kepuasan kerja tinggi maka lebih berpeluang untuk berkomitmen organisasional tinggi. Diharapkan pihak Rumah Sakit Prikasih lebih memerhatikan kepuasan kerja perawat, agar mereka mampu mempertahankan dan meningkatkan komitmen terhadap Rumah Sakit Prikasih.
\end{abstract}

Kata Kunci : Kepuasan Kerja, Komitmen Organisasional, Perawat, Rumah Sakit

\begin{abstract}
Based on data from Risnakes 2017, the job satisfaction of hospital staff in DKI Jakarta is mostly in the moderate $(50.1 \%)$ and high $(25,2 \%)$ category. Nurses with high job satisfaction will help others more enthusiastically and exceed normal expectations in their work that will lead to commitment to the hospital where they work. The purpose of this study is to analyze the relationship between job satisfaction with organizational commitment of nurses in Prikasih Hospital. This study used cross sectional design with chi square test. The sample in this study were 104 nurses taken by proportional sampling technique. The results showed the prevalence of high organizational commitment was 58 nurses (55.8\%) and high job satisfaction as many as 52 nurses (50\%), high job satisfaction have a high organizational commitment of 36 nurses $(69.2 \%)$, and there is a relationship between job satisfaction and organizational commitment ( $p$-value $=$ 0,010 ) with $\mathrm{PR}=1.875$ dan $95 \%$ CI : 1,173-2,998. Nurses who have high job satisfaction have the opportunity to have high organizational commitment. It is expected that the Prikasih hospital is give more attention to the job satisfaction of nurses, so they are able to defend and increase commitment to the Prikasih hospital.
\end{abstract}

Keywords: Job Satisfaction, Organizational Commitment, Nurse, Hospital 


\section{Pendahuluan}

Berdasarkan Undang-Undang RI Nomor 44 Tahun 2009 tentang Rumah Sakit, mencantumkan bahwa persyaratan sumber daya manusia yang harus dimiliki oleh rumah sakit salah satunya yaitu tenaga keperawatan. ${ }^{1}$ Tenaga perawat merupakan tenaga yang selama 24 jam melayani pasien secara langsung dalam proses pengobatan maupun pemulihan kesehatan pasien. ${ }^{2}$ Menurut data rekapitulasi BPPSDMK per Desember 2016, jumlah perawat di Indonesia merupakan jumlah terbanyak yang didayagunakan rumah sakit di antara tenaga kesehatan lainnya yaitu sebanyak 58,26\% perawat. ${ }^{3}$ Umumnya rumah sakit umum swasta kelas C di DKI Jakarta mempunyai jumlah ratarata perawat $64,4 \%$ di rumah sakit. ${ }^{4}$

Pihak rumah sakit perlu memerhatikan hal yang dibutuhkan oleh tenaga perawat yang dimilikinya, supaya para perawat bisa berdedikasi secara penuh kepada rumah sakit dan memiliki komitmen terhadap rumah sakit tempatnya bekerja. ${ }^{5}$ Komitmen rendah akan berdampak pada turn over pegawai, tingginya ketidakhadiran, kerja, pegawai menjadi lebih lamban dan rendahnya kualitas kinerja, kurang kesungguhan bertahan di organisasi serta kurang loyalitas pada organisasi. ${ }^{6}$

Faktor yang dapat memengaruhi komitmen organisasional salah satunya adalah kepuasan kerja $^{7}$, apabila kepuasan kerja dalam organisasi terpenuhi maka akan muncul dengan sendirinya kepercayaan pegawai bahwa organisasinya benar-benar peduli terhadap pegawainya, hal ini berdampak juga terhadap meningkatnya komitmen pegawai terhadap organisasi. ${ }^{7}$ Kepuasan kerja memiliki hubungan yang kuat dengan komitmen organisasional, dimana kepuasan kerja akan dapat meningkatkan namun dapat juga menurunkan tingkat komitmen organisasional pegawai. ${ }^{8}$

Berdasarkan hasil Riset Tenaga Kesehatan (Risnakes) 2017 kepuasan kerja staf rumah sakit di DKI Jakarta sebagian besar di kategori sedang yaitu $50,1 \%$ sedangkan rendah $24,7 \%$ dan tinggi sebanyak 25,2\%. Berdasarkan kategori kepemilikan rumah sakit, rumah sakit swasta memiliki persentase kepuasan kerja rendah lebih tinggi dibandingkan dengan rumah sakit pemerintah non TNI/POLRI dan pemerintah TNI/ POLRI, dengan persentase yaitu pada rumah sakit swasta kepuasan kerja rendah $24,6 \%$ sedangkan rumah sakit pemerintah non TNI/ POLRI 23,5\% dan rumah sakit pemerintah TNI/POLRI 18,9\% ${ }^{4}$. Perawat yang puas dengan pekerjaannya akan tampak lebih berbicara positif tentang rumah sakit tempatnya bekerja, membantu orang lain dengan lebih antusias, dan jauh melebihi harapan yang normal dalam pekerjaannya, serta akan menimbulkan komitmen kepada rumah sakit tempatnya bekerja. ${ }^{5}$

Penelitian yang dilakukan Kristianto pada tahun 2011 dengan 130 perawat di RSUD Tugurejo Semarang, didapatkan bahwa kepuasan kerja mempunyai pengaruh positif terhadap komitmen organisasional, dapat disimpulkan jika semakin tinggi kepuasan kerja perawat maka 
semakin tinggi juga komitmen perawat bagi rumah sakit. ${ }^{9}$

Penelitian telah dilakukan oleh Ami Cahya S. pada tahun 2014 mengenai kepuasan kerja karyawan di Rumah Sakit Prikasih. Didapatkan dari hasil penelitian bahwa karyawan merasa kurang puas terhadap kebijakan dan peraturan di Rumah Sakit Prikasih seperti informasi yang didapatkan mengenai suatu penetapan hari libur, shift kerja, dan kebijakan lainnya. Karyawan juga kurang puas dengan gaji dan intensif yang diterima. ${ }^{10}$

Penelitian juga telah dilakukan di Rumah Sakit Prikasih oleh Rahmawati pada tahun 2015 mengenai turn over intention perawat di Rumah Sakit Prikasih, Didapatkan hasil penelitiannya yaitu sebanyak $52,9 \%$ responden merasa tidak terlalu senang bekerja di Rumah Sakit Prikasih dan tidak merasakan bahwa permasalahan di Rumah Sakit Prikasih merupakan permasalahan mereka; sebanyak 70,6\% merasa sikap loyal terhadap organisasi; dan $66,6 \%$ responden bersedia meninggalkan Rumah Sakit Prikasih jika responden mendapatkan tawaran pekerjaan lain. ${ }^{11}$

Berdasarkan data rekapitulasi turn over di Rumah Sakit Prikasih, selama tahun 2016 perawat yang keluar dari Rumah Sakit Prikasih sebanyak 38 orang, angka yang keluar turun pada tahun 2017 yaitu sebanyak 27 orang (16\%), dan pada tahun 2018 perawat yang keluar meningkat dibandingkan tahun sebelumnya yaitu sebanyak 34 orang $(21 \%)$. Menurut Gillies, normalnya perawat yang keluar dari rumah sakit sebesar 5$10 \%$ per tahun, dan disebut tinggi jika melebihi dari $10 \% .{ }^{2}$ Dapat disimpulkan bahwa turn over perawat mengalami kenaikan yang cukup tinggi pada tahun 2018 di Rumah Sakit Prikasih, hal ini menandakan masih kurangnya komitmen organisasional di Rumah Sakit Prikasih.

Penelitian mengenai kepuasan kerja pada karyawan dan hubungan komitmen organisasional dan turn over pada perawat sudah pernah dilakukan di Rumah Sakit Prikasih, sedangkan penelitian mengenai adakah hubungan antara kepuasan kerja dengan komitmen organisasional pada perawat belum pernah dilakukan di Rumah Sakit Prikasih. Berdasarkan uraian di atas, maka penelitian ini penting untuk dilakukan dan dibahas dengan tujuan mengetahui gambaran dan hubungan kepuasan kerja dan komitmen organisasional pada perawat di Rumah Sakit Prikasih.

\section{Metode Penelitian}

Penelitian ini menggunakan penelitian kuantitatif dengan desain studi cross sectional. Populasi yang diambil yaitu seluruh perawat pelaksana yang bertugas di Rumah Sakit Prikasih tahun 2019 yaitu sebanyak 140 perawat. Agar representatif dapat terpenuhi, maka besar sampel dapat menggunakan rumus besar sampel. ${ }^{12}$ Salah satu rumus penentuan sampel yang dapat digunakan dalam penelitian yang memiliki populasi cukup banyak atau jumlahnya diatas 100 atau wilayahnya yang luas, yaitu dengan menggunakan rumus slovin. ${ }^{13}$ Berdasarkan rumus slovin dengan menggunakan $95 \%$ sebagai tingkat kelonggaran ketidaktelitian terhadap kesalahan 
pengambilan sampel yang masih bisa ditolerir, didapatkan sampel sebanyak 104 perawat. Sampel dipilih dengan teknik proporsional sampling yaitu dengan memproporsikan tiap instalasi unit perawat/ pelayanan kesehatan medis di Rumah Sakit Prikasih. Waktu penelitian dari persiapan sampai pelaksanaan yaitu bulan Februari sampai Juni 2019.

Cara pengumpulan data dalam penelitian ini terdiri dari data primer dan sekunder. Data sekunder didapatkan dari rekapitulasi yang dilakukan oleh Unit Sumber Daya Manusia (SDM) Rumah Sakit Prikasih, yaitu data jumlah tenaga perawat setiap unit pada tahun 2019 dan turn over perawat pada tahun 2016, 2017, dan 2018. Data primer diperoleh dari wawancara dengan menggunakan angket skala likert, untuk pernyataan variabel komitmen organisasional modifikasi dari pengukuran komitmen organisasional Mayer dan Allen yang terdiri dari tiga komponen pernyataan yaitu komitmen afektif, kontinu dan normatif. Komitmen afektif berkaitan dengan hubungan atau keterikatan individu dengan organisasi karena memiliki nilai dan tujuan yang sama, ${ }^{6}$ komitmen kontinu berkaitan dengan karena adanya rasa kebutuhan ${ }^{14}$ serta adanya pengukuran keuntungan ekonomi, ${ }^{15}$ dan komitmen normatif didasarkan pada keyakinan pegawai akan tanggung jawabnya terhadap organisasi. Pernyataan variabel kepuasan kerja yaitu modifikasi dari alat ukur Job Satisfaction Survey (JSS) yang terdiri dari sembilan aspek yaitu gaji, promosi, supervisi, tunjangan, penghargaan, prosedur operasional, rekan kerja, sifat pekerjaan, dan komunikasi.

Peneliti memodifikasi kuesioner yang ada dengan hanya menggunakan empat pilihan jawaban dengan data ordinal, yaitu sangat tidak setuju, tidak setuju, setuju, dan sangat setuju. Peneliti mempertimbangkan semakin banyak tingkatan yang dibuat maka akan semakin sulit dipilih oleh orang yang mempunyai daya diferensi (perbuatan membedakan) kecil. Selain itu pilihan yang ganjil jumlahnya menimbulkan kecenderungan responden memilih jawaban yang terdapat di tengah. Oleh karena itu, dibuat pilihan genap supaya responden berpikir untuk memilihnya. ${ }^{16}$

Uji coba alat ukur atau instrumen dilakukan di Rumah Sakit Jati Sampurna Kota Bekasi, pada 30 orang perawat yang bertugas langsung menangani pasien. Setelah dilakukan uji validitas dan reliabilitas angket komitmen organisasional dari 18 menjadi 12 item $(r>0,361)$ dan angket kepuasan kerja dari 36 menjadi 22 item $(\mathrm{r}>0,361)$. Perhitungan uji reliabiltas dilakukan setelah melakukan uji validitas dan mereduksi soal-soal yang tidak valid. Hasil perhitungan reliabilitas menunjukan bahwa untuk variabel komitmen organisasional dengan cronbach alpha 0,745 dan variabel kepuasan kerja dengan cronbach alpha 0,860. Hasil tersebut menunjukkan bahwa instrumen dinyatakan valid.

Proses analisis data dalam penelitian dengan analisis univariat dan bivariat dan menggunakan aplikasi statistik yaitu IBM SPSS 
Statistics 20. Pada analisis bivariat memakai rumus uji chi-square untuk menganalisis hubungan antara variabel kepuasan kerja dengan komitmen organisasional.

\section{Hasil}

Berdasarkan hasil penelitian pada Tabel 1 menunjukan bahwa dari 104 responden perawat di Rumah Sakit Prikasih, sebagian besar responden berjenis kelamin perempuan yaitu berjumlah 89 responden $(85,6 \%)$.

Tabel 1. Distribusi Frekuensi Karakteristik Responden

\begin{tabular}{lcc}
\hline $\begin{array}{l}\text { Karakteristik } \\
\text { Responden }\end{array}$ & Frekuensi & $\begin{array}{c}\text { Persentase } \\
(\%)\end{array}$ \\
\hline 1. Jenis Kelamin & & \\
a. Laki-laki & 15 & 14,4 \\
b. Perempuan & 89 & 85,6 \\
2. Usia (tahun) & & \\
a. 20-25 & 32 & 30,8 \\
b. 26-35 & 55 & 52,9 \\
c. 36-45 & 13 & 12,5 \\
d. 46-55 & 4 & 3,8 \\
3. Masa Kerja (tahun) & & \\
a. <1 & 10 & 9,6 \\
b. 1-10 & 78 & 75 \\
c. >10 & 16 & 15,4 \\
4. Pendidikan & & \\
Terakhir & & \\
a. D3 & 77 & 74 \\
b. S1/ Ners & 25 & 24 \\
c. Lainnya & 2 & 2 \\
5. Status & & \\
Kepegawaian & & \\
a. Tetap & 79 & 76 \\
b. Kontrak & 25 & 24 \\
6. Status Perkawinan & & \\
a. Menikah & 72 & 69,2 \\
b. Belum & 32 & 30,8 \\
\hline \multicolumn{1}{l}{ Menikah } & & \\
\hline
\end{tabular}

Usia perawat sebagian besar 26-35 tahun yaitu sebanyak 55 responden (52,9\%). Sebagian besar masa kerja responden yaitu 1-10 tahun sebanyak 78 responden (75\%). Pendidikan akhir perawat sebagian besar D3 Keperawatan yaitu 77 responden $(74 \%)$. Status kepegawaian perawat sebagian besar pegawai tetap yaitu sebanyak 79 responden (76\%). Sebagian besar responden berstatus sudah menikah yaitu sebanyak 72 responden $(69,2 \%)$.

Berdasarkan Tabel 2 menunjukkan bahwa dari 104 perawat Rumah Sakit Prikasih yang menjadi responden, lebih banyak responden yang berkomitmen tinggi yaitu sebanyak 58 responden $(55,8 \%)$. Menunjukkan juga bahwa kepuasan kerja yang rendah dengan kepuasan kerja tinggi seimbang yaitu masing-masing berjumlah 52 responden $(50 \%)$.

Tabel 2. Distribusi Frekuensi Responden Berdasarkan Komitmen Organisasional dan Kepuasan Kerja

\begin{tabular}{lccc}
\hline \multicolumn{1}{c}{ Variabel } & Kategori & Frekuensi & \% \\
\hline Komitmen & Rendah & 46 & 44,2 \\
Organisasional & Tinggi & 58 & 55,8 \\
\hline Kepuasan & Rendah & 52 & 50 \\
Kerja & Tinggi & 52 & 50 \\
\hline
\end{tabular}

Berdasarkan tabel 3 menunjukkan bahwa perawat yang berkomitmen tinggi dapat dilihat dari dimensi komitmen afektif yaitu sebagian besar responden setuju $(51,9 \%)$ bahwa dengan senang hati menghabiskan masa karirnya di RS Prikasih. Selain itu komitmen yang tinggi pada perawat dapat juga dilihat dari jawaban komitmen normatif yaitu mayoritas responden sebanyak 63 responden $(60,6 \%)$ menjawab setuju bahwa tidak akan meninggalkan rumah sakit saat ini, karena masih memiliki kewajiban atau tanggung jawab terhadap pekerjaan mereka. Mayoritas responden 
juga setuju (62,5\%) bahwa RS Prikasih pantas (71,2\%) menjawab setuju bahwa mendapatkan loyalitas dari mereka. Dilihat dari mempertahankan pekerjaan di RS merupakan jawaban responden pada komitmen kontinu suatu kebutuhan dan keinginan mereka.

dimana mayoritas responden yaitu 74 responden

Tabel 3 Distribusi Jawaban Responden Terkait Komitmen Organisasional

\begin{tabular}{|c|c|c|c|c|c|}
\hline & Komitmen Organisasional & STS & TS & $\mathbf{S}$ & $\mathbf{S S}$ \\
\hline \multirow{3}{*}{1.} & Afektif & & & & \\
\hline & $\begin{array}{l}\text { a. Dengan senang hati menghabiskan masa karir di RS } \\
\text { Prikasih }\end{array}$ & $\begin{array}{c}4 \\
(3,8 \%)\end{array}$ & $\begin{array}{c}32 \\
(30,8 \%)\end{array}$ & $\begin{array}{c}54 \\
(51,9 \%)\end{array}$ & $\begin{array}{c}14 \\
(13,5 \%)\end{array}$ \\
\hline & $\begin{array}{l}\text { b. Merasa masalah yang terjadi di rumah sakit adalah masalah } \\
\text { mereka juga. }\end{array}$ & $\begin{array}{c}6 \\
(5,8 \%)\end{array}$ & $\begin{array}{c}30 \\
(28,8 \%)\end{array}$ & $\begin{array}{c}58 \\
(55,8 \%)\end{array}$ & $\begin{array}{c}10 \\
(9,6 \%)\end{array}$ \\
\hline \multirow[t]{7}{*}{2.} & Kontinu & & & & \\
\hline & $\begin{array}{l}\text { a. Menginginkan meninggalkan RS tapi lebih memilih } \\
\text { bertahan }\end{array}$ & $\begin{array}{c}11 \\
(10,6 \%)\end{array}$ & $\begin{array}{c}34 \\
(33,7 \%)\end{array}$ & $\begin{array}{c}44 \\
(42,3 \%)\end{array}$ & $\begin{array}{c}14 \\
(13,5 \%)\end{array}$ \\
\hline & $\begin{array}{l}\text { b. Meninggalkan RS akan membuat sebagian kehidupan } \\
\text { mereka terganggu }\end{array}$ & $\begin{array}{c}15 \\
(14,4 \%)\end{array}$ & $\begin{array}{c}58 \\
(55,8 \%)\end{array}$ & $\begin{array}{c}29 \\
(27,9 \%)\end{array}$ & $\begin{array}{l}2 \\
(1,9 \%)\end{array}$ \\
\hline & $\begin{array}{l}\text { c. Mempertahankan pekerjaan di RS merupakan suatu } \\
\text { kebutuhan dan keinginan }\end{array}$ & $\begin{array}{c}1 \\
(1 \%)\end{array}$ & $\begin{array}{c}11 \\
(10,6 \%)\end{array}$ & $\begin{array}{c}74 \\
(71,2 \%)\end{array}$ & $\begin{array}{c}18 \\
(17,3 \%)\end{array}$ \\
\hline & $\begin{array}{l}\text { d. Tidak mempunyai banyak alasan untuk meninggalkan } \\
\text { rumah sakit }\end{array}$ & $\begin{array}{c}6 \\
(5,8 \%)\end{array}$ & $\begin{array}{c}36 \\
(34,6 \%)\end{array}$ & $\begin{array}{c}59 \\
(56,7 \%)\end{array}$ & $\begin{array}{c}3 \\
(2,9 \%)\end{array}$ \\
\hline & $\begin{array}{l}\text { e. Akan sulit mencari alternatif pekerjaan di tempat lain jika } \\
\text { meninggalkan RS }\end{array}$ & $\begin{array}{c}19 \\
(18,3 \%)\end{array}$ & $\begin{array}{c}37 \\
(35,6 \%)\end{array}$ & $\begin{array}{c}39 \\
(37,5 \%)\end{array}$ & $(8,7 \%)$ \\
\hline & $\begin{array}{l}\text { f. Akan mengorbankan banyak hal penting jika meninggalkan } \\
\text { RS }\end{array}$ & $\begin{array}{c}7 \\
(41 \%)\end{array}$ & $\begin{array}{c}41 \\
(39,4 \%)\end{array}$ & $\begin{array}{c}48 \\
(46,2 \%)\end{array}$ & $\begin{array}{c}8 \\
(7,7 \%)\end{array}$ \\
\hline \multirow[t]{5}{*}{3.} & Normatif & & & & \\
\hline & $\begin{array}{l}\text { aeskipun menguntungkan, tetapi mereka merasa } \\
\text { meninggalkan rumah sakit bukanlah hal yang tepat }\end{array}$ & $\begin{array}{c}9 \\
(8,7 \%)\end{array}$ & $\begin{array}{c}52 \\
(50 \%)\end{array}$ & $\begin{array}{c}35 \\
(33,7 \%)\end{array}$ & $\begin{array}{c}8 \\
(7,7 \%)\end{array}$ \\
\hline & b. Akan merasa bersalah jika meninggalkan RS sekarang & $(6,7 \%)$ & $\begin{array}{c}33 \\
(31,7 \%)\end{array}$ & $\begin{array}{c}54 \\
(51,9 \%)\end{array}$ & $\begin{array}{c}10 \\
(9,6 \%)\end{array}$ \\
\hline & $\begin{array}{l}\text { c. Rumah Sakit Prikasih pantas mendapatkan loyalitas dari } \\
\text { mereka. }\end{array}$ & $\begin{array}{l}4 \\
(3,8 \%)\end{array}$ & $\begin{array}{c}19 \\
(18,3 \%)\end{array}$ & $\begin{array}{c}65 \\
(62,5 \%)\end{array}$ & $\begin{array}{c}16 \\
(15,4 \%)\end{array}$ \\
\hline & $\begin{array}{l}\text { d. Tidak akan meninggalkan rumah sakit saat ini, karena } \\
\text { masih memiliki kewajiban atau tanggung jawab terhadap } \\
\text { pekerjaan mereka. }\end{array}$ & $\begin{array}{l}5 \\
(4,8 \%)\end{array}$ & $\begin{array}{c}16 \\
(15,4 \%)\end{array}$ & $\begin{array}{c}63 \\
(60,6 \%)\end{array}$ & $\begin{array}{c}20 \\
(19,2 \%)\end{array}$ \\
\hline
\end{tabular}

Berdasarkan tabel 4 menunjukkan bahwa kepuasan kerja perawat di Rumah Sakit Prikasih jumlahnya seimbang untuk kategori kepuasan kerja tinggi dengan kepuasan kerja rendah. Kepuasan kerja rendah pada perawat dapat dilihat dari distribusi jawaban responden, dimana masih rendahnya kepuasan kerja pada dimensi tunjangan, yaitu sebagian besar jawaban responden, sebanyak 47 responden $(45,2 \%)$ setuju dan 20 responden $(19,3 \%)$ sangat setuju bahwa mereka tidak puas dengan tunjangan yang diterima. Serta sebagian responden yaitu 36 responden $(34,6 \%)$ tidak setuju dan 23 responden $(22,1 \%)$ sangat tidak setuju bahwa tunjangan yang mereka terima sama besar dengan rumah sakit lain.

Sedangkan kepuasan kerja perawat yang tinggi dapat dilihat dari distribusi jawaban 
perawat, yaitu sebagian besar responden menjawab bahwa mereka setuju $(51,9 \%)$ digaji dengan jumlah yang layak untuk pekerjaan yang mereka lakukan. Kepuasan kerja perawat yang tinggi dapat dilihat juga dari sebagian besar responden setuju menyukai pekerjaan yang mereka lakukan $(64,4 \%)$, nyaman dengan rekan kerja mereka (67,3\%), setuju bahwa menyukai supervisor $(77,9 \%)$, serta setuju bahwa peraturan yang ketat jarang menghambat mereka untuk melakukan pekerjaan dengan baik $(67,3 \%)$.

Tabel 4. Distribusi Jawaban Responden Terkait Kepuasan Kerja

\begin{tabular}{|c|c|c|c|c|}
\hline Kepuasan Kerja & STS & TS & $\mathbf{S}$ & SS \\
\hline \multicolumn{5}{|l|}{ 1. Gaji } \\
\hline $\begin{array}{l}\text { a. Digaji dengan jumlah yang layak untuk pekerjaan yang } \\
\text { dilakukan. }\end{array}$ & $\begin{array}{c}15 \\
(14,4 \%)\end{array}$ & $\begin{array}{c}29 \\
(27,9 \%)\end{array}$ & $\begin{array}{c}54 \\
(51,9 \%)\end{array}$ & $\begin{array}{c}6 \\
(5,8 \%)\end{array}$ \\
\hline $\begin{array}{l}\text { b. Merasa puas dengan kesempatan mereka memperoleh } \\
\text { kenaikan gaji. }\end{array}$ & $\begin{array}{c}2 \\
(1,9 \%)\end{array}$ & $\begin{array}{c}37 \\
(35,6 \%)\end{array}$ & $\begin{array}{c}52 \\
(50 \%)\end{array}$ & $\begin{array}{c}13 \\
(12,5 \%)\end{array}$ \\
\hline \multicolumn{5}{|l|}{ 2. Promosi } \\
\hline $\begin{array}{l}\text { a. Perawat yang bekerja dengan baik memiliki kesempatan } \\
\text { untuk dipromosikan dengan adil oleh rumah sakit. }\end{array}$ & $\begin{array}{c}4 \\
(3.8 \%)\end{array}$ & $\begin{array}{c}21 \\
(20.2 \%)\end{array}$ & $\begin{array}{c}56 \\
(53,8 \%)\end{array}$ & $\begin{array}{c}23 \\
(22,1 \%)\end{array}$ \\
\hline b. Puas dengan kesempatan untuk dipromosikan & $\begin{array}{c}2 \\
(1,9 \%)\end{array}$ & $\begin{array}{c}32 \\
(30,8 \%)\end{array}$ & $\begin{array}{c}60 \\
(57,7 \%)\end{array}$ & $\begin{array}{c}10 \\
(9,6 \%)\end{array}$ \\
\hline \multicolumn{5}{|l|}{ 3. Supervisi } \\
\hline a. Superv & $\begin{array}{c}26 \\
(25 \%)\end{array}$ & $\begin{array}{c}59 \\
(56,7 \%)\end{array}$ & $\begin{array}{c}17 \\
(16,3 \%)\end{array}$ & $\begin{array}{c}2 \\
(1,9 \%)\end{array}$ \\
\hline b. Supervisor kurang peduli terhadap perasaan bawahannya. & $\begin{array}{c}14 \\
(13,5 \%)\end{array}$ & $\begin{array}{c}70 \\
(67,3 \%)\end{array}$ & $\begin{array}{c}19 \\
(18,3 \%)\end{array}$ & $\begin{array}{c}1 \\
(1 \%)\end{array}$ \\
\hline c. Menyukai supervisor mereka. & $\begin{array}{c}1 \\
(1 \%) \\
\end{array}$ & $\begin{array}{c}8 \\
(7,7 \%) \\
\end{array}$ & $\begin{array}{c}81 \\
(77,9 \%) \\
\end{array}$ & $\begin{array}{c}14 \\
(13,5 \%) \\
\end{array}$ \\
\hline \multicolumn{5}{|l|}{ 4. Tunjangan } \\
\hline a. Tidak puas denga & $\begin{array}{c}2 \\
(1,9 \%)\end{array}$ & $\begin{array}{c}35 \\
(33,7 \%)\end{array}$ & $\begin{array}{c}47 \\
(45,2 \%)\end{array}$ & $\begin{array}{c}20 \\
(19,3 \%)\end{array}$ \\
\hline $\begin{array}{l}\text { b. Tunjangan yang diterima sama baiknya dengan rumah sakit } \\
\text { lain. }\end{array}$ & $\begin{array}{c}23 \\
(22,1 \%)\end{array}$ & $\begin{array}{c}36 \\
(34,6 \%)\end{array}$ & $\begin{array}{c}38 \\
(36,5 \%)\end{array}$ & $\begin{array}{c}7 \\
(6,7 \%)\end{array}$ \\
\hline \multicolumn{5}{|l|}{ 5. Penghargaan } \\
\hline $\begin{array}{l}\text { Pekerjaan yang mereka lakukan tidak dihargai dengan } \\
\text { baik. }\end{array}$ & $\begin{array}{c}14 \\
(13,5 \%)\end{array}$ & $\begin{array}{c}61 \\
(58,7 \%)\end{array}$ & $\begin{array}{c}28 \\
(26,9 \%)\end{array}$ & $\begin{array}{c}1 \\
(1 \%)\end{array}$ \\
\hline \multicolumn{5}{|l|}{ 6. Prosedur Operasional } \\
\hline $\begin{array}{l}\text { a. Prosedur yang ada di rumah sakit menyulitkan perawat } \\
\text { untuk melakukan pekerjaan dengan baik. }\end{array}$ & $\begin{array}{c}11 \\
(10,6 \%)\end{array}$ & $\begin{array}{c}63 \\
(60,6 \%)\end{array}$ & $\begin{array}{c}27 \\
(26 \%)\end{array}$ & $\begin{array}{c}3 \\
(2,9 \%)\end{array}$ \\
\hline $\begin{array}{l}\text { b. Peraturan yang sangat ketat jarang menghambat usaha } \\
\text { mereka untuk melakukan pekerjaan dengan baik. }\end{array}$ & $\begin{array}{c}4 \\
(3,8 \%) \\
\end{array}$ & $\begin{array}{c}22 \\
(21,2 \%) \\
\end{array}$ & $\begin{array}{c}70 \\
(67,3 \%) \\
\end{array}$ & $\begin{array}{c}8 \\
(7,7 \%) \\
\end{array}$ \\
\hline \multicolumn{5}{|l|}{ 7. Rekan Kerja } \\
\hline $\begin{array}{l}\text { a. Harus bekerja lebih keras karena rekan kerja mereka kurang } \\
\text { kompeten. }\end{array}$ & $\begin{array}{c}15 \\
(14,4 \%)\end{array}$ & $\begin{array}{c}55 \\
(52,9 \%)\end{array}$ & $\begin{array}{c}29 \\
(27,9 \%)\end{array}$ & $\begin{array}{c}5 \\
(4,8 \%)\end{array}$ \\
\hline b. Nyaman dengan rekan kerja mereka. & $\begin{array}{c}3 \\
(2,9 \%)\end{array}$ & $\begin{array}{c}1 \\
(1 \%)\end{array}$ & $\begin{array}{c}70 \\
(67,3 \%)\end{array}$ & $\begin{array}{c}30 \\
(28,8 \%)\end{array}$ \\
\hline c. Banyak percecokan dan perselisihan di tempat kerja. & $\begin{array}{c}17 \\
(16,3 \%)\end{array}$ & $\begin{array}{c}63 \\
(60,6 \%)\end{array}$ & $\begin{array}{c}24 \\
(23,1 \%)\end{array}$ & 0 \\
\hline
\end{tabular}




\begin{tabular}{|c|c|c|c|c|c|}
\hline \multicolumn{2}{|r|}{ Kepuasan Kerja } & STS & TS & $\mathbf{S}$ & SS \\
\hline \multicolumn{6}{|c|}{ 8. Sifat Pekerjaan } \\
\hline \multicolumn{2}{|c|}{ a. pekerjaan mereka tidak bermakna. } & $\begin{array}{c}24 \\
(23,1 \%)\end{array}$ & $\begin{array}{c}57 \\
(54,8 \%)\end{array}$ & $\begin{array}{c}20 \\
(19,2 \%)\end{array}$ & $\begin{array}{c}3 \\
(2,9 \%)\end{array}$ \\
\hline \multicolumn{2}{|r|}{ b. Banyak pekerjaan yang dilakukan di rumah sakit. } & $\begin{array}{c}2 \\
(1,9 \%)\end{array}$ & $\begin{array}{c}58 \\
(55,8 \%)\end{array}$ & $\begin{array}{c}42 \\
(40,4 \%)\end{array}$ & $\begin{array}{c}2 \\
(1,9 \%)\end{array}$ \\
\hline \multicolumn{6}{|c|}{ 9. Komunikasi } \\
\hline & $\begin{array}{l}\text { Komunikasi yang ada di rumah sakit berjalan dengan baik } \\
\text { (lancar). }\end{array}$ & $\begin{array}{c}1 \\
(1 \%)\end{array}$ & $\begin{array}{c}13 \\
(12,5 \%)\end{array}$ & $\begin{array}{c}74 \\
(71,2 \%)\end{array}$ & $\begin{array}{c}16 \\
(15,4 \%)\end{array}$ \\
\hline b. & Tujuan rumah sakit prikasih tidak cukup jelas bagi mereka. & $\begin{array}{c}9 \\
(8,7 \%)\end{array}$ & $\begin{array}{c}62 \\
(59,6 \%)\end{array}$ & $\begin{array}{c}30 \\
(28,8 \%)\end{array}$ & $\begin{array}{c}3 \\
(2,9 \%)\end{array}$ \\
\hline & $\begin{array}{l}\text { Mereka merasa tidak mengetahui apa yang terjadi di rumah } \\
\text { sakit. }\end{array}$ & $\begin{array}{c}5 \\
(4,8 \%)\end{array}$ & $\begin{array}{c}35 \\
(33,7 \%)\end{array}$ & $\begin{array}{c}62 \\
(59,6 \%)\end{array}$ & $\begin{array}{c}2 \\
(4,8 \%)\end{array}$ \\
\hline d. & $\begin{array}{l}\text { Tidak mendapat petunjuk yang cukup jelas terkait tugas } \\
\text { yang mereka lakukan. }\end{array}$ & $\begin{array}{c}9 \\
(8,7 \%)\end{array}$ & $\begin{array}{c}67 \\
(64,4 \%)\end{array}$ & $\begin{array}{c}28 \\
(26,9 \%)\end{array}$ & 0 \\
\hline
\end{tabular}

Hasil uji chi-square pada Tabel 5, dari 104 responden sebagian besar responden dengan kepuasan kerja tinggi memiliki komitmen organisasional tinggi sebanyak 36 responden $(69,2 \%)$ dan $p$-value $0,010<\alpha 0,05$ berarti terdapat hubungan antara kepuasan kerja dengan komitmen organisasional pada perawat di Rumah
Sakit Prikasih. Nilai PR (Prevalence Ratio) sebesar 1,875 , artinya perawat yang memperoleh kepuasan kerja tinggi memiliki peluang 1,875 kali untuk mempunyai komitmen organisasional tinggi saat bekerja di Rumah Sakit Prikasih dibandingkan dengan perawat yang mempunyai kepuasan kerja rendah.

Tabel 5. Analisis Hubungan Antara Komitmen Organisasional dengan Kepuasan Kerja

\begin{tabular}{|c|c|c|c|c|c|c|c|c|}
\hline \multirow[t]{3}{*}{ Kepuasan Kerja } & \multicolumn{4}{|c|}{ Komitmen Organisasional } & \multicolumn{2}{|c|}{ Total } & \multirow[t]{3}{*}{$p$-value } & \multirow[t]{3}{*}{ PR (95\% CI) } \\
\hline & \multicolumn{2}{|c|}{ Rendah } & \multicolumn{2}{|c|}{ Tinggi } & & & & \\
\hline & $\mathbf{N}$ & $\%$ & $\mathbf{N}$ & $\%$ & $\mathbf{N}$ & $\%$ & & \\
\hline Rendah & 30 & 57,7 & 22 & 42,3 & 52 & 100 & 0,010 & 1,875 \\
\hline Tinggi & 16 & 30,8 & 36 & 69,2 & 52 & 100 & & $(1,173-2,998)$ \\
\hline
\end{tabular}

\section{Pembahasan}

Berdasarkan hasil penelitian menunjukkan bahwa sebagian besar perawat yang memiliki komitmen organisasional tinggi lebih banyak berada pada kategori kepuasan kerja tinggi dibandingkan dengan kepuasan kerja rendah. Pada penelitian ini perawat yang berkomitmen tinggi disebabkan dari dimensi komitmen normatif yang dimiliki yaitu mayoritas responden tidak akan meninggalkan rumah sakit saat ini, karena masih memiliki kewajiban atau tanggung jawab terhadap pekerjaan mereka dan merasa Rumah Sakit Prikasih pantas mendapatkan loyalitas dari mereka. Individu yang mempunyai komitmen normatif tinggi cenderung bertahan dalam pekerjaannya karena merasa sebagai suatu kewajiban ataupun tugasnya. Individu yang berkomitmen tinggi memunculkan perasaan 
loyalitas terhadap organisasinya dan bersedia untuk bertahan dalam organisasi tersebut. ${ }^{17}$

Komitmen yang tinggi pada perawat juga bisa disebabkan mayoritas responden mempunyai komitmen kontinu, dimana mereka memilih mempertahankan pekerjaan di Rumah Sakit Prikasih karena suatu kebutuhan dan keinginan mereka. Seseorang bertahan di dalam suatu organisasi karena membutuhkan gaji atau seseorang tersebut tidak mempunyai alternatif pekerjaan di tempat lain atau bisa disebabkan organisasi yang sekarang banyak memberikan keuntungan yang tidak didapatkannya di tempat lain. ${ }^{18}$

Semakin tinggi komitmen seseorang terhadap suatu organisasi, maka akan semakin rendah tingkat absensi dan turn over, serta semakin kecilnya kemungkinan untuk mencari pekerjaan di tempat lain. ${ }^{19}$ Hasil penelitian ini didukung oleh penelitian Manoppo dkk tahun 2014 yang dilakukan terhadap perawat di Rumah Sakit Bhakti Wira Tamtama Semarang. Hasil tersebut menunjukkan bahwa sebagian responden berkomitmen tinggi dibandingkan dengan yang berkomitmen rendah. Komitmen pegawai yang rendah mempunyai dampak negatif bagi organisasi. ${ }^{20}$ Organisasi tidak akan mampu membuat suatu perubahan dengan cepat dan menampilkan kinerja yang baik jika tidak memunculkan komitmen pada pegawainya. ${ }^{21}$

Berdasarkan hasil penelitian menunjukkan bahwa kepuasan kerja rendah dan kepuasan kerja tinggi memiliki jumlah yang seimbang. Kepuasan kerja yang rendah pada perawat di Rumah Sakit
Prikasih disebabkan masih rendahnya kepuasan kerja pada dimensi tunjangan yaitu sebagian besar mereka tidak puas dengan tunjangan yang diterima dan tunjangan yang mereka terima sama besar dengan rumah sakit lain. Sejalan dengan penelitian yang dilakukan Farhadjafari dkk tahun 2014 mengemukakan bahwa tingkat kepuasan terkait aspek tunjangan pada perawat di Tehran Teaching Hospital lebih rendah dibandingkan aspek lainnya. ${ }^{22}$ Menurut hasil penelitian Auliani dan Wulyani tahun 2017 tunjangan yang diberikan organisasi ke pegawainya seharusnya dilakukan secara adil sesuai dengan kontribusi yang telah diberikan oleh pegawai kepada organisasi sehingga pegawai dan organisasi bisa saling merasakan kepuasan. ${ }^{23}$

Kepuasan kerja perawat yang tinggi dapat disebabkan dari sebagian besar responden menyukai pekerjaan yang mereka lakukan, nyaman dengan rekan kerja mereka, menyukai supervisor mereka, dan peraturan yang ketat jarang menghambat mereka untuk melakukan pekerjaan dengan baik. Berdasarkan penelitian Mariyanti tahun 2014 pekerja biasanya lebih menyenangi pekerjaan yang dapat memberi kesempatan mereka menggunakan keterampilan dan kemampuan dalam menjalankan tugas. ${ }^{5}$ Demikian pula mempunyai rekan kerja yang ramah serta mendukung seseorang dalam bekerja akan membuat seseorang tersebut mempunyai kepuasan kerja yang tinggi. Seseorang dengan tingkat kepuasan kerja yang tinggi akan mempunyai perasaan positif terhadap pekerjaan mereka, sedangkan seseorang yang tidak puas 
memiliki perasaan negatif terhadap pekerjaan mereka. $^{24}$

Kepuasan kerja sebagai suatu evaluasi yang menggambarkan seseorang atas perasaan sikapnya senang atau tidak senang, puas atau tidak puas dalam bekerja. ${ }^{25}$ Ketika pegawai mempunyai kepuasan kerja, pegawai biasanya jarang tidak masuk, dapat berkontribusi positif, dan dapat tinggal lebih lama di organisasinya. Sebaliknya jika pegawai mempunyai kepuasan rendah, maka akan memunculkan sikap dan perilaku negatif dalam pekerjaannya. ${ }^{26}$

\section{Hubungan Kepuasan Kerja dengan Komitmen Organisasional}

Hasil penelitian menyatakan bahwa sebagian besar responden dengan kepuasan kerja tinggi memiliki komitmen organisasional tinggi sebanyak 36 responden $(69,2 \%)$. Hasil uji chisquare didapatkan adanya hubungan antara kepuasan kerja dengan komitmen organisasional pada perawat di Rumah Sakit Prikasih. Perawat yang memperoleh kepuasan kerja tinggi memiliki peluang 1,875 kali untuk mempunyai komitmen tinggi saat bekerja di Rumah Sakit Prikasih dibandingkan dengan perawat yang mempunyai kepuasan rendah.

Hasil penelitian ini sejalan dengan penelitian yang dilakukan Ho dkk tahun 2009 di dua rumah sakit di Taiwan Selatan dengan responden sebanyak 532 perawat, yang menunjukan jika ada pengaruh positif antara kepuasan kerja dengan komitmen organisasional. ${ }^{27}$ Berdasarkan penelitian yang dilakukan Kristianto dkk tahun 2011 pada perawat di RSUD Tugurejo Semarang, didapatkan bahwa kepuasan kerja memiliki pengaruh positif bagi komitmen organisasional, sehingga disimpulkan bahwa semakin tinggi kepuasan kerja perawat semakin tinggi juga komitmen perawat terhadap rumah sakit. ${ }^{9}$

Penelitian ini tidak sejalan dengan penelitian yang dilakukan Triwijayanti dkk tahun 2017 di Rumah Sakit Pusri Palembang yang menyatakan bahwa tidak ada hubungan kepuasan kerja perawat dengan komitmen organisasi. Hal ini disebabkan kepuasan seseorang berasal dari persepsi orang tersebut terhadap pekerjaannya, dimana orang yang merasa puas tidak selalu membuat orang itu berkomitmen, karena kemauan orang untuk berkomitmen dengan organisasi disebabkan adanya perasaan ingin, kebutuhan atau bahkan untung dan rugi bukan hanya karena kepuasan orang tersebut terhadap pekerjaannya. ${ }^{28}$

Hasil penelitian menyatakan sebagian besar responden dengan kepuasan kerja tinggi memiliki komitmen tinggi. Kepuasan kerja memberikan hubungan yang positif dengan komitmen organisasi. ${ }^{20}$ Karyawan yang relatif puas dengan pekerjaannya akan lebih berkomitmen pada organisasi dibandingkan dengan karyawan yang memiliki kepuasan yang rendah. ${ }^{29}$ Demikian juga bagi perawat, perawat yang puas akan tampak lebih berbicara positif tentang rumah sakit mereka bekerja, membantu orang lain dengan lebih antusias, dan jauh melebihi harapan yang normal dalam pekerjaan 
mereka, serta akan menimbulkan komitmen kepada rumah sakit tempat mereka bekerja. ${ }^{5}$

\section{Keterbatasan Penelitian}

Pengambilan data pada penelitian ini menggunakan angket, sehingga data yang diperoleh dari jawaban responden terbatas dan masih kurang untuk menggali komitmen organisasional dan kepuasan kerja perawat di Rumah Sakit Prikasih. Keterbatasan lainnya yang ditemui peneliti adalah banyaknya item-item pernyataan yang tidak valid. Hal ini dikarenakan keterbatasan dalam menerjemahkan instrumen kuesioner adaptasi, sehingga apa yang diinginkan oleh peneliti dengan pemahaman dari responden tidak sesuai.

\section{Kesimpulan dan Saran}

Berdasarkan tujuan dan hasil penelitian yang dilakukan terhadap 104 perawat di Rumah Sakit Prikasih, maka dapat diambil kesimpulan yaitu sebagian besar perawat yang memiliki komitmen organisasional tinggi berada pada kategori kepuasan kerja tinggi dibandingkan dengan kepuasan kerja rendah. Maka terdapat hubungan antara kepuasan kerja dengan komitmen organisasional pada perawat di Rumah Sakit Prikasih.

Berdasarkan hasil penelitian masih banyak perawat yang memiliki komitmen tinggi di Rumah Sakit Prikasih, diharapkan bagi pihak manajemen dapat memberikan perhatian lebih agar dapat meningkatkan lagi perawat yang berkomitmen, yang akan membuat perawat merasa bahwa rumah sakit bagian dari hidupnya dan perawat akan berusaha bersikap loyal terhadap rumah sakit. Kepuasan kerja perawat di Rumah Sakit Prikasih, masih rendah dalam hal tunjangan. Maka disarankan pihak rumah sakit dapat mengevaluasi sistem tunjangan yang berlaku dengan memperhatikan dari segala aspek seperti besarnya tanggung jawab, prestasi kerja yang dihasilkan, usia serta adil dalam memberikan tunjangan.

Diharapkan bagi peneliti berikutnya untuk mencari faktor lain yang berhubungan dengan komitmen organisasional seperi faktor individu, situasional dan posisional.

\section{Ucapan Terimakasih}

Ucapan terima kasih penulis sampaikan kepada seluruh pihak yang terlibat dalam penelitian ini, terutama kepada Dekan Fakultas Ilmu Kesehatan Universitas Pembangunan "Veteran" Jakarta, Dr. drg. Wahyu Sulistiadi, MARS, serta Kepala Program Studi Kesehatan Masyarakat, Putri Permatasari, SKM, MKM, dan pihak Rumah Sakit Prikasih yang telah memberikan izin dan membantu penulis dalam melakukan penelitian.

\section{Daftar Pustaka}

1. Undang-Undang RI Nomor 44 Tahun 2009 tentang Rumah Sakit.

2. Mardiana I, Hubeis AVS, Panjaitan NK. Hubungan Kepuasan Kerja dengan Turnover Intentions pada Perawat Rumah Sakit Dhuafa. Manajemen IKM. 2014;9(2):119-30. 
3. Kementerian Kesehatan RI. Situasi Tenaga Keperawatan Indonesia. Pusat Data dan Informasi. 2017;

4. Kementerian Kesehatan RI. Buku 2 Laporan Riset Ketenagaan di Bidang Kesehatan (RISNAKES) 2017: Rumah Sakit. 2 ed. Jakarta; 2018.

5. Mariyanti E. Kepuasaan Kerja terhadap Komitmen Organisasi (Studi Kasus pada Perawat Rumah Sakit Swasta di Kota Padang). Komtekinfo Fakultas Ilmu Komputer. 2014;1(1):38-45.

6. Priansa DJ. Perencanaan dan Pengembangan SDM. Bandung: Alfabeta; 2016.

7. Wibowo. Perilaku dalam Organisasi. Jakarta: Rajawali Pers; 2016.

8. Tania A. Pengaruh Motivasi Kerja dan Kepuasan Kerja terhadap Komitmen Organisasional Karyawan PT . DAI KNIFE di Surabaya. AGORA. 2013;1(3).

9. Kristianto D. Pengaruh Kepuasan Kerja Terhadap Kinerja Karyawan dengan Komitmen Organisasional sebagai Variabel Intervening (Studi pada RSUD Tugurejo Semarang). 2011;20(2):52-63.

10. Shefria AC. Pengaruh Motivasi, Lingkungan Kerja dan Ekspektasi Kerja terhadap Kepuasan Kerja Karyawan di Rumah Sakit Prikasih Jakarta. Skripsi. 2014;

11. Rahmawati E. Analisis Hubungan Budaya Organisa dengan Turnover Intention Perawat Rumah Sakit Prikasih Tahun
2015. J Adm Rumah Sakit. 2016;

12. Swarjana IK. Metodologi Penelitian Kesehatan (Edisi Revisi). Yogyakarta: Andi; 2015.

13. Carsel S. Metodologi Penelitian Kesehatan dan Pendidikan,. Yogyakarta: Penebar Media; 2018.

14. Yusuf RM, Syarif D. Komitmen Organisasi: Definis, Dipengaruhi dan Mempengaruhi. Makassar: Nas Media Pustaka; 2018.

15. Kusumaputri ES. Komitmen pada Perubahan Organisasi (Perubahan Organisasi dalam Perspektif Islam dan Psikologi). Yogyakarta: Deepublish; 2018.

16. Sandjaja B, Heriyanto A. Panduan Penelitian Edisi Revisi. Jakarta: Prestasi Pustakaraya; 2011.

17. Muliyadi, Hamid AYS, Mustikasari. Kinerja Perawat Berdasarkan Komitmen pada Organisasi dan Lingkungan Kerja Perawat. Keperawatan Indonesia. 2010;14(1):14-9.

18. Sopiah. Perilaku Organisasi. Yogyakarta: Andi; 2008.

19. Batmomolin A, Noya LH. Hubungan Faktor Individu dengan Komitmen Perawat pada Organisasi di Rumah Sakit Hati Kudus Langgur Kabupaten Maluku Tenggara Tahun 2013. Jurnal Kesehat Terpadu. 2015;6(1):31-44.

20. Manoppo IA, Rejeki S, Ulliya S. Hubungan Organisasi Lini dan Kepuasan 
Kerja Perawat dengan Komitmen

Organisasi. Manajemen Keperawatan.

2014;2(2):85-93.

21. Januardha J, Nurwidawati D. Perbedaan

Komitmen Organisasi Karyawan Tetap dan Karyawan Outsourcing Pada PT.

Bank Pembangunan Daerah "X."

Psikologi Teori dan Terapan.

2014;5(1):38-44.

22. Farhadjafari,

Seyedehsanbeladianbehbahan,

Gharahgozloi M, Behzadtadayyon. Staff'

s Job Satisfaction Survey in Tehran' s

Teaching Hospitals. Biomed Pharmacol. 2014;7(1):9-16.

23. Auliani R, Wulanyani NMS. Faktor-

Faktor Kepuasan Kerja pada Karyawan

Perusahaan Perjalanan Wisata di

Denpasar. Psikologi Udayana.

2017;4(2):426-34.

24. Robbins S, Judge TA. Perilaku

Organisasi. 12 ed. Jakarta: Salemba Empat; 2012.

25. Iskandar, Yuhansyah. Pengaruh Motivasi dan Ketidakamanan Kerja Terhadap Penilaian Kinerja yang Berdampak kepada Kepuasan Kerja. Surabaya: Media
Sahabat Cendekia; 2018.

26. Suwatno. Manajemen SDM dalam Organisasi Publik dan Sains. Bandung: Alfabeta; 2014.

27. Ho W, Chang CS, Shih Y, Liang R- Da. Effects of job rotation and role stress among nurses on job satisfaction and organizational commitment. BMC Heal Serv Res. 2009;9(8):1-10.

28. Triwijayanti R, Romiko, Muda M. Hubungan antara Kepuasan Kerja Perawat dengan Komitmen Organisasi di Ruang Rawat Inap. In: Seminar dan Workshop Nasional Keperawatan "Implikasi Perawatan Paliatif pada Bidang Kesehatan" [Internet]. 2017. Tersedia pada:

http://conference.unsri.ac.id/index.php/S

NK/article/view/746

29. Karambut CA, Noormijati EAT. Analisis Pengaruh Kecerdasan Emosional, Stres Kerja dan Kepuasan Kerja terhadap Komitmen Organisasional (Studi pada Perawat Unit Rawat Inap RS Panti Waluya Malang). Jurnal Aplikasi Manajemen. 2012;10(3). 